\title{
Usefulness of the indocyanine green fluorescence endoscope in endonasal transsphenoidal surgery
}

\author{
Takuichiro Hide, MD, PhD, Shigetoshi Yano, MD, PhD, Naoki Shinojima, MD, PhD, \\ and Jun-ichi Kuratsu, MD, PhD
}

Department of Neurosurgery, Kumamoto University Graduate School of Medical Science, Kumamoto, Japan

\begin{abstract}
OBJECT To avoid disorientation during endoscopic endonasal transsphenoidal surgery (ETSS), the confirmation of anatomical landmarks is essential. Neuronavigation systems can be pointed at exact sites, but their spatial resolution power is too low for the detection of vessels that cannot be seen on MR images. On Doppler ultrasonography the shape of concealed arteries and veins cannot be visualized. To address these problems, the authors evaluated the clinical usefulness of the indocyanine green (ICG) endoscope.

METHODS The authors included 38 patients with pituitary adenomas $(n=26)$, tuberculum sellae meningiomas $(n=$ 4), craniopharyngiomas $(n=3)$, chordomas $(n=2)$, Rathke's cleft cyst $(n=1)$, dermoid cyst $(n=1)$, or fibrous dysplasia $(n=1)$. After opening the sphenoid sinus and placing the ICG endoscope, the authors injected $12.5 \mathrm{mg}$ of ICG into a peripheral vein as a bolus and observed the internal carotid arteries (ICAs), cavernous sinus, intercavernous sinus, and pituitary.

RESULTS The ICA was clearly identified by a strong fluorescence signal through the dura mater and the covering thin bone. The intercavernous and cavernous sinuses were visualized a few seconds later. In patients with tuberculum sellae meningiomas, the abnormal tumor arteries in the dura were seen and the vague outline of the attachment was identified. At the final inspection after tumor removal, perforators to the brain, optic nerves, chiasm, and pituitary stalk were visualized. ICG fluorescence signals from the hypophyseal arteries were strong enough to see and spread to the area of perfusion with the passage of time.
\end{abstract}

CONCLUSIONS The ICA and the patent cavernous sinus were detected with the ICG endoscope in real time and at high resolution. The ICG endoscope is very useful during ETSS. The authors suggest that the real-time observation of the blood supply to the optic nerves and pituitary helps to predict the preservation of their function.

http://thejns.org/doi/abs/10.3171/2014.9.JNS14599

KEY WORDS indocyanine green fluorescence endoscope; endoscopic endonasal transsphenoidal surgery; pituitary adenoma; meningioma; craniopharyngioma; chordoma; surgical technique

$\mathrm{E}$ NDOSCOPIC transnasal transsphenoidal surgery (ETSS) is a standard procedure to treat sellar and parasellar lesions. ${ }^{6-8,10}$ It facilitates the effective initial management of pituitary adenomas and maximal tumor removal. ${ }^{8,10}$ The areas accessible by endoscopes have increased. Kassam et al. ${ }^{6}$ reported median sagittal plane and paramedian plane endoscopic approaches. They gained access from the cribriform plate to the odontoid in the median sagittal plane and advanced the paramedian coronal plane approach into the anterior, middle, and posterior fossae.

During ETSS, anatomical landmarks such as the ca- rotid prominence, optic prominence, and the opticocarotid recess are very important for good orientation. However, they are sometimes buried in bone and/or tumors, which may result in disorientation. While neuronavigation systems can be pointed at exact sites, their spatial resolution may be inadequate to, for example, avoid bleeding from vessels that are not detected on MRI scans. Doppler ultrasonography can reveal arterial flow in real time; however, its spatial resolution is too low for a demonstration of the shape of concealed arteries, and it is difficult to obtain information on the venous system.

During vascular surgery, angiography and Doppler ul-

ABBREVIATIONS $A C A=$ anterior cerebral artery; $A C O A=$ anterior communicating artery; $C S$ = cavernous sinus; $E T S S$ = endoscopic endonasal transsphenoidal surgery; $I C A=$ internal carotid artery; ICG = indocyanine green; ICS = intercavernous sinus; 5-ALA = 5-aminolevulinic acid.

SUBMITTED March 16, 2014. ACCEPTED September 10, 2014.

INCLUDE WHEN CITING Published online February 27, 2015; DOI: 10.3171/2014.9.JNS14599.

DISCLOSURE The authors report no conflict of interest concerning the materials or methods used in this study or the findings specified in this paper. 
trasonography have been used to investigate the blood flow into clipped aneurysms and the patency of the parent artery and perforators. ${ }^{1,2}$ Microscope-integrated indocyanine green (ICG) videoangiography has been used to confirm the real-time blood flow, ${ }_{13,15,19,21,22}$ and endoscope-integrated ICG videoangiography has been useful in verifying the patency of vessels hidden from microscopic view., ${ }^{3,11,12}$

We used an ICG endoscope during ETSS to gain clear information on vessels. We used the instrument to discern the fine edge of the internal carotid artery (ICA) and to check the patency of the intercavernous sinus (ICS) and the cavernous sinus (CS) behind the dura mater. We also investigated time-related changes in the intensity of fluorescence signals from the ICA, ICS, pituitary, and tumors such as pituitary adenomas, craniopharyngiomas, and meningiomas. In addition, we checked the patency of perforators of the optic nerve and the pituitary stalk during and after tumor resection.

\section{Methods \\ Patients}

All patients underwent ETSS at Kumamoto University Hospital in the period from April to December 2013. This retrospective study was performed in accordance with the institutional ethics committee at Kumamoto University Hospital, and all patients provided prior written informed consent for inclusion in this study. We included 38 patients (19 males and 19 females; age range 11-84 years, mean age 54.5 years) with pituitary adenomas $(n=26)$, tuberculum sellae meningiomas $(n=4)$, craniopharyngiomas $(n=$ $3)$, chordomas $(n=2)$, Rathke's cleft cyst $(n=1)$, dermoid cyst $(n=1)$, or fibrous dysplasia $(n=1)$.

\section{ICG Fluorescence}

The ICG compound ( $25 \mathrm{mg}$ ), purchased from DaiichiSankyo, was dissolved in $10 \mathrm{ml}$ of sterile water, and $5 \mathrm{ml}$ of the solution (12.5 mg of ICG) was injected into a peripheral vein as a bolus. For flushing we used $10 \mathrm{ml}$ of saline. The maximum absorption and emission wavelength of ICG in water are $780 \mathrm{~nm}$ and $805 \mathrm{~nm}$, respectively; in plasma they are $800 \mathrm{~nm}$ and $825 \mathrm{~nm} .{ }^{4}$

\section{Endoscope and ICG Endoscope}

Rigid $0^{\circ}$ and $30^{\circ}$ endoscopes $(4 \mathrm{~mm}$ in diameter, 18 $\mathrm{cm}$ in length; KARL STORZ) are commonly used for ETSS. To detect the ICA and the patent CS, a different endoscope is needed. The ICG endoscope we used features a straight forward $0^{\circ}$ telescope $(5.8 \mathrm{~mm}$ in diameter, $19 \mathrm{~cm}$ in length), an IMAGE $1 \mathrm{H} 3-\mathrm{Z}$ FI Three-Chip ICG FULL HD Camera Head, an Image 1 HUB HD camera control unit, and a Cold Light Fountain D-LIGHT P (all KARL STORZ). ${ }^{3}$ The light source can be converted from white to near-infrared light with a foot switch. We placed the ICG endoscope in a suitable position under white light and then switched to near-infrared light, whereupon the fluorescence signals from the ICG flow in the ICA and CS became visible.

\section{Measurement of the ICG Fluorescent Signals}

All data of the endoscopic images displayed intraoperatively on a video monitor were recorded digitally.
After the operation, to investigate changes in the fluorescent intensity signals in the individual structures, we saved the recorded ICG endoscopic images as 1-secondinterval pictures and imported these into Photoshop (Adobe Systems Inc.). The time of the first detection of ICG in the ICA was designated as Second 1. To obtain the average intensity data in each structure, we measured the fluorescent intensity as blue color values per pixel at more than 4 points in the imported pictures using the Photoshop color sampler tool. The color value ranged from 0 to 255 . Graphs of the time at peak and the peak color value were drawn using GraphPad Prism (version 6).

\section{Results \\ ICA, Cavernous Sinus, and Pituitary}

Good orientation with respect to the ICA and CS is important for successful ETSS. However, in some of the cases, the carotid prominence, optic prominence, and the opticocarotid recess were buried in bone and the tumor. We first attempted to identify the ICA under the ICG endoscope. We generally followed the bolus injection of ICG by flushing with $10 \mathrm{ml}$ of saline; $10-15$ seconds later, a strong fluorescent signal was seen in the ICA. It could be detected through the dura mater even when it was covered by mucosa and the thin bone of the carotid prominence as in the representative patient with chordoma (Fig. 1A-D). The ICS and CS were also clearly identified a few seconds after detection of the ICA (Fig. 1E).

We next investigated the time-related changes in the intensity of the fluorescence signals in different structures. The ICA was usually clearly identified by its strong fluorescence signal (Fig. 1D). At 3-5 seconds after its detection, the fluorescence signal from the ICS and CS was seen (Fig. 1E), and then the mucosa in the sphenoid sinus started to be visualized (Fig. 1E and F). At 30 seconds after ICA detection, the fluorescence signal from the normal pituitary appeared; its intensity grew gradually and approximately 60 seconds after ICA detection, it became stronger than in surrounding structures (Fig. 1F). However, the stronger ICG signal from the mucosa rendered the edges of structures unclear as the background signal was strong (Fig. 1F).

In another patient with a pituitary adenoma, upon removal of the mucosa, the fine edge of the ICA was seen during the observation period (Fig. 2A-D). After resecting the bone of the sellar floor, there was strong signal intensity from the dural artery and pituitary adenoma (Fig. $2 \mathrm{E}$ and $\mathrm{F}$ ). However, a blood clot in the endoscopic field absorbed the excitation (near infra-red) light and inhibited IGC signal emission (Fig. 2E and F).

\section{Attachment of the Tuberculum Sellae Meningioma}

The control of bleeding is essential for the safe removal of meningiomas. During ETSS, the operative field is small and the ability to manipulate instruments is limited. Consequently, the identification and management of existing attachments are highly important. We used an ICG endoscope to confirm the blood supply and the drainage route of the tuberculum sellae meningiomas.

After excision of the bone around the planum sphe- 

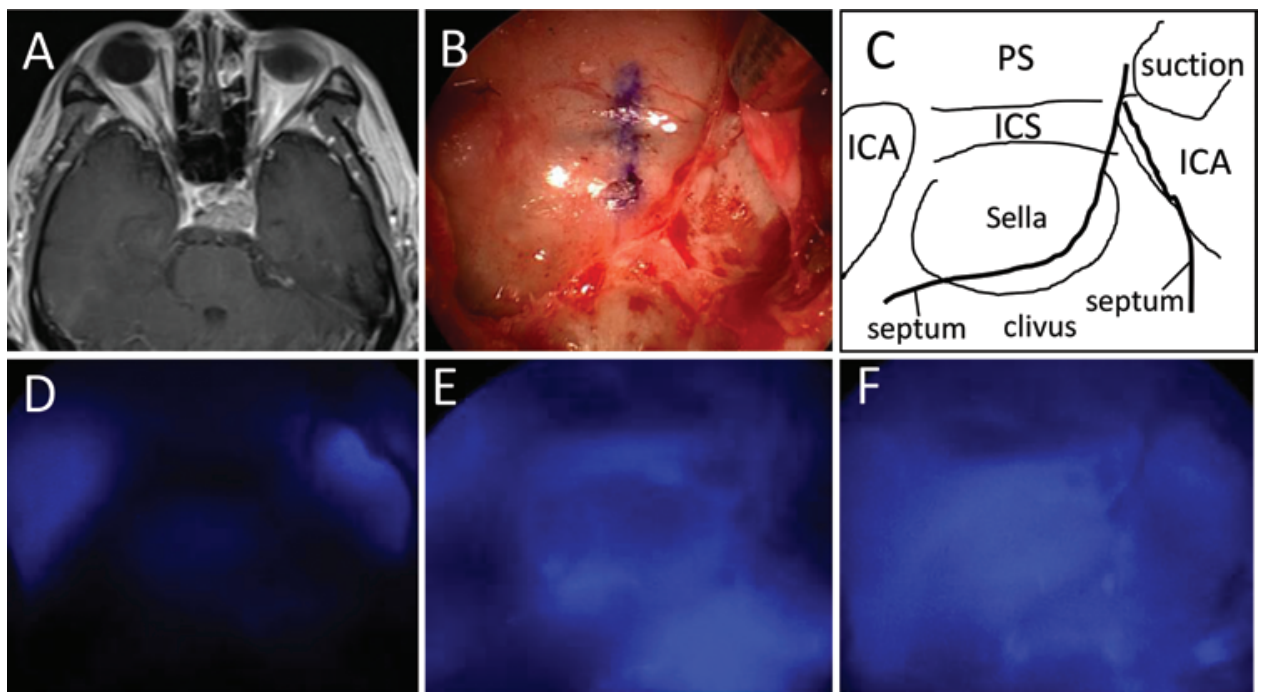

FIG. 1. Chordoma. A: Axial T1-weighted MR image showing a chordoma in the clival region. B: Endoscopic view of the sellar floor. The blue line marks the midline. C: Anatomical schema of the endoscopic images. D-F: View of the ICA (D), ICS (E), and pituitary (F) under the ICG endoscope. PS = planum sphenoidale. Figure is available in color online only.

noidale, the tuberculum sellae, and the sellar floor, we injected a bolus of $12.5 \mathrm{mg}$ of ICG (Fig. 3A-C). Abnormal tumor arteries in the dura and the vague outline of the attachment were identified at 3 and 15 seconds, respectively, after ICA detection (Fig. 3C-F). At the same time, the size of the ICS and the draining route from the tumor could be evaluated (Fig. 3E and F). This enabled us to determine the appropriate placement of the dural incision to avoid bleeding.

\section{Perforators and Pituitary Stalk}

The optic nerves, pituitary stalk, and pituitary gland are usually compressed by pituitary adenomas, craniopharyngiomas, and meningiomas. We used an ICG endoscope to confirm the normal blood flow and to distinguish the normal pituitary stalk and gland from these tumors.

In the representative patient who harbored a meningioma (Fig. 3), we injected ICG after total resection. The bilateral anterior cerebral arteries (ACAs), anterior communicating artery $(\mathrm{ACOA})$, recurrent arteries of Heubner, and other perforators to the frontal lobes were identified by strong fluorescent signals. Then, the blood flow in the superior hypophyseal arteries to the optic nerves and pituitary stalk was visualized in real time at higher spatial resolution (Fig. 3G-L).

MRI scans of a craniopharyngioma showed a suprasellar tumor with a cyst (Fig. 4A and B). After opening the dura the surface of the tumor was seen (Fig. 4C). The tumor wall was cut, and yellowish cyst fluid was evacuated. To distinguish the tumor from the pituitary stalk, we injected ICG. The stalk was identified by a strong fluorescent signal; however, the signal from the solid tumor was weak (Fig. 4D-F). After total resection, ICG was injected again as a bolus. The flow in the preserved superior hypophyseal arteries that perfused the optic nerves and stalk was visualized and the pituitary was detected gradually (Fig. 4E-G). Our observations suggest that differences in the intensity of the fluorescence signals make it possible
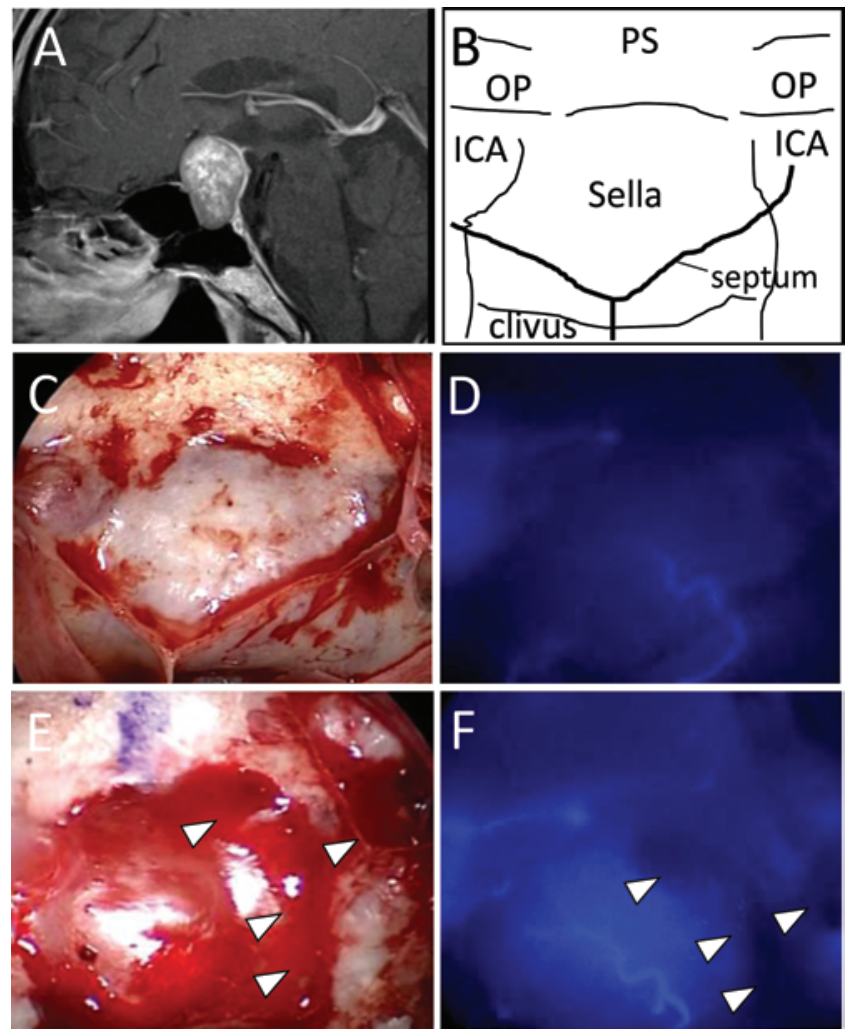

FIG. 2. Nonfunctioning pituitary adenoma. A: Axial T1-weighted MR image showing a heterogeneously enhanced mass lesion in the sella turcica. B: Anatomical scheme of the endoscopic images. C: Endoscopic view of the sellar floor covered by bone. D: ICG endoscopic view showing the ICA and a small artery. E: Endoscopic view of the sellar floor without bone. Note the blood collection (arrowheads). F: ICG endoscopic view showing the ICA and a small artery. Collected blood (arrowheads) inhibits the emission of ICG fluorescence. OP = optic prominence. Figure is available in color online only. 

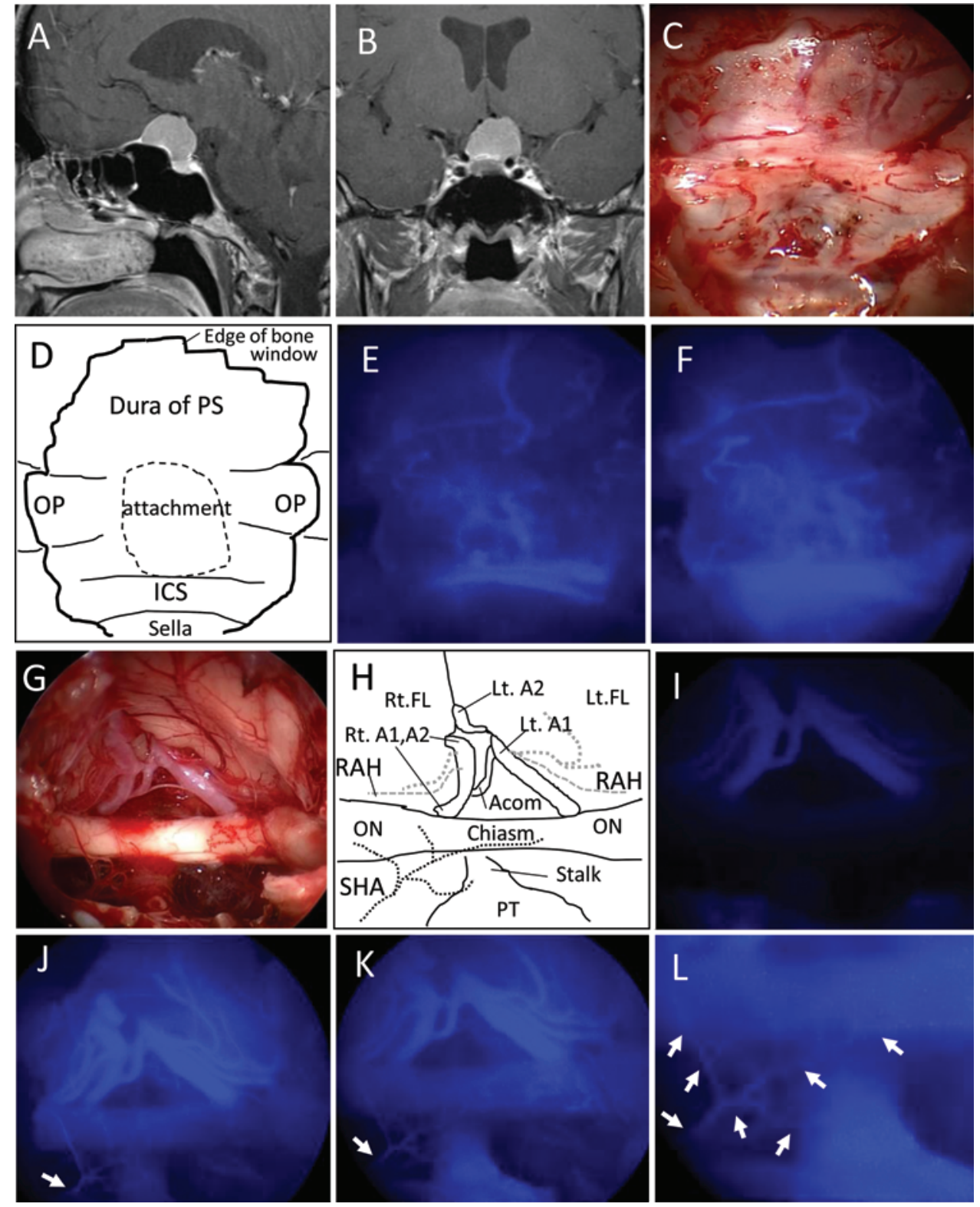

FIG. 3. Tuberculum sellae meningioma. A and B: Sagittal (A) and coronal (B) contrast-enhanced T1-weighted MR images showing a heterogeneously enhanced mass lesion in the tuberculum sellae. C: Endoscopic view of the tuberculum sellae. D: Anatomical scheme of the endoscopic images. E and F: ICG endoscopic view showing abnormal tumor arteries in the dura (E) and the vague outline of the tumor attachment $(F)$. G and $H$ : Endoscopic view of the tuberculum sellae after total removal of the tumor $(G)$ and anatomical scheme $(\mathrm{H})$. I: ICG endoscopic view showing the $\mathrm{A}_{1}$ portion of the ACA, ACoA, recurrent artery of Heubner (gray broken lines in $\mathrm{H}$ ), perforators (gray dotted lines in $\mathrm{H}$ ), and pituitary stalk, at the time of $\mathrm{A}_{1}$ detection. J: Three seconds later the superior hypophyseal artery (arrow; black dotted lines in $\mathrm{H}$ ) was visualized. $\mathrm{K}$ : Twelve seconds after $\mathrm{A}_{1}$ detection the fluorescence signal from the superior hypophysial artery (arrow) and the pituitary stalk increased. L: Higher magnification view of panel K, showing perfusion by the superior hypophyseal artery (arrows) of the optic nerve, chiasm, and pituitary stalk. Acom $=$ anterior communicating artery; $A 1=A_{1}$ segment; $A 2=A_{2}$ segment; $F L=$ frontal lobe; $O N=$ optic nerve; $P T$ = pituitary; $R A H=$ recurrent artery of Heubner; SHA = superior hypophyseal artery. Figure is available in color online only.

to distinguish between the pituitary stalk and craniopharyngiomas.

In some patients with pituitary adenomas the arachnoid membrane, tumor capsule, and the paper-thin normal pituitary descended together after total intracapsular resection. We injected ICG again to try to identify the residual pituitary. The ICG signal was detected in a small part of the inverted pituitary at the site where a high intensity area was seen on the preoperative T1-weighted MRI scan, suggesting that it was the posterior lobe of the pituitary (Fig. $5 \mathrm{~A}-\mathrm{D})$.

In summary, not only the ACA, ACoA, and recurrent arteries of Heubner, but also perforators such as the superior hypophyseal artery and other vessels to the brain, the 

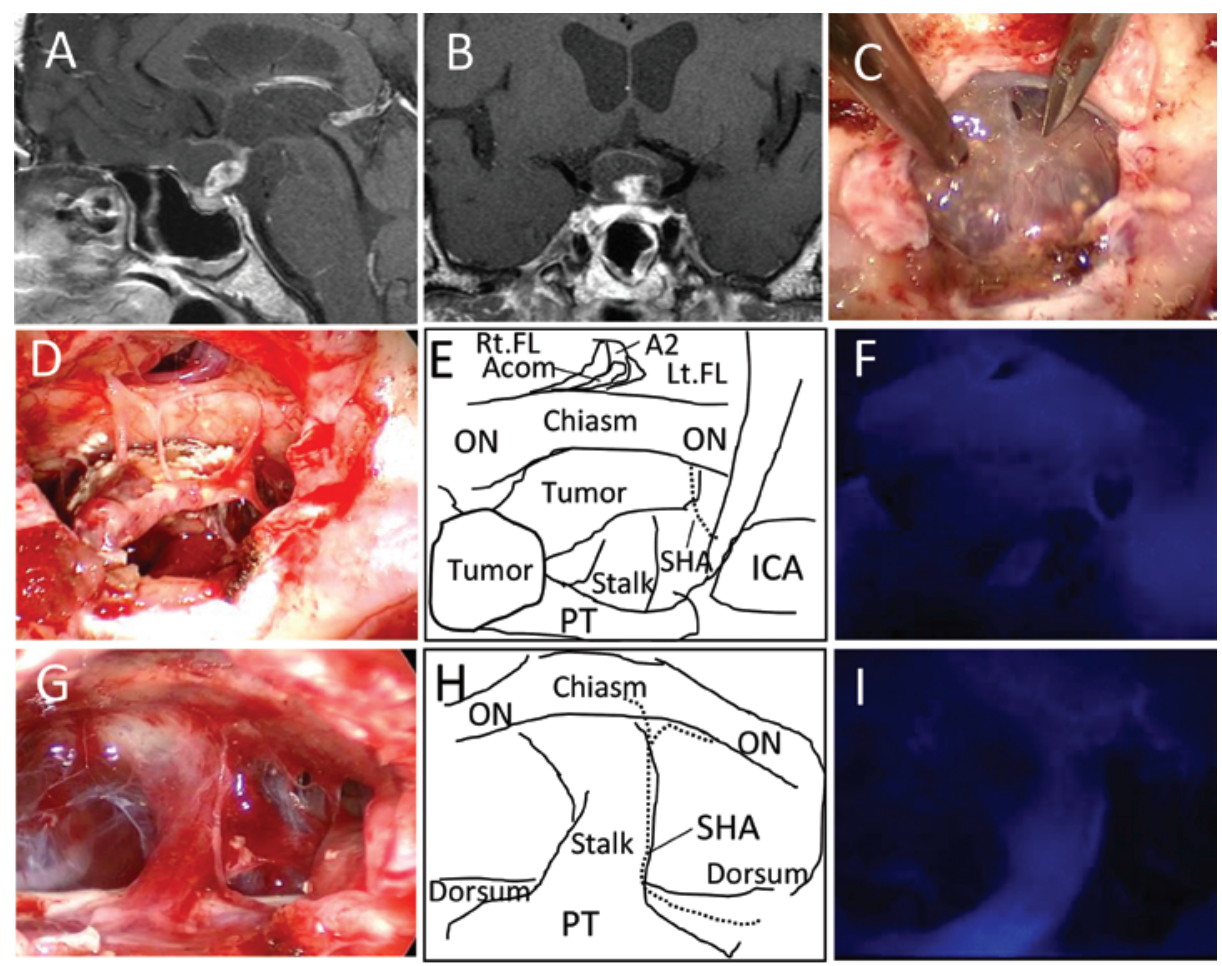

FIG. 4. Craniopharyngioma. A and B: Sagittal (A) and coronal (B) contrast-enhanced T1-weighted MR images showing a heterogeneously enhanced mass lesion with a cyst in the sellar and suprasellar region. C and D: Endoscopic view of the craniopharyngioma after opening the dura (C) and evacuation of the cyst fluid (D). E: Anatomical scheme of the endoscopic images shown in Fig. 4D. F: ICG endoscopic view showing a strong fluorescent signal from the left ICA and the pituitary stalk. The signal from the tumor tissue is weak. G-I: Endoscopic view after total removal of the tumor $(\mathrm{G})$ and anatomical scheme $(\mathrm{H})$. The pituitary stalk and pituitary gland show fluorescent signals (I). Figure is available in color online only.

optic nerves, chiasm, and pituitary stalk could be visualized (Figs. 3G-L and 4D-I). This is of clinical significance with respect to the anatomical and functional preservation of the superior hypophyseal arteries because the ICG fluorescence signals revealed not only their patency but also the structures they perfused.

\section{Change of Fluorescent Intensity With the Passage of Time}

Postoperatively, the recorded ICG endoscopic images were saved as digital pictures at 1-second intervals and were imported into Photoshop. The fluorescent intensity was measured as the color value of blue. The average color value at the each target structure was calculated from more than 4 points. The time of the first detection of ICG in the ICA was designated as Second 1. To investigate changes in the color value of the ICA, ICS, and normal pituitary, data from individual patients were aggregated and displayed as 3 graphs that show the center of the color value and the range from the minimum to the maximum color value at 1-second intervals. Characteristically, the time at peak color value was around 6 seconds in the ICA $(n=10), 15$ seconds in the ICS $(n=8)$, and 50 seconds in the normal pituitary $(n=4)($ Fig. 6A). The ICA was detected first and the ICS very shortly thereafter. The color value of the normal pituitary increased gradually and exceeded that of the ICA and ICS after 30 seconds.

Next, we focused on the time at peak color value and the peak color value in individual patients. The median of
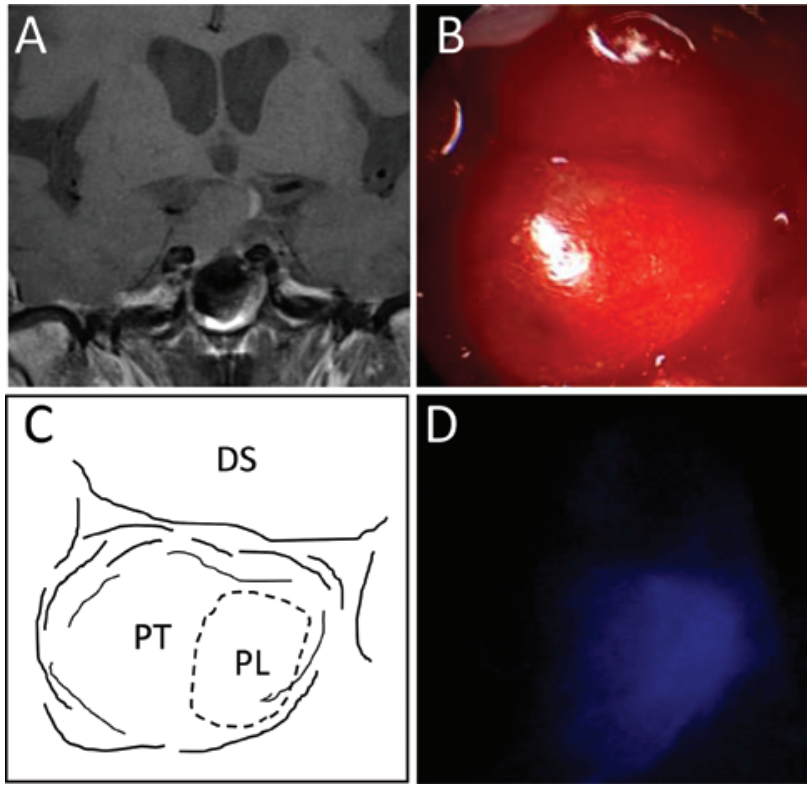

FIG. 5. Pituitary adenoma. A: Coronal T1-weighted coronal MR image showing a small high-intensity area on the upper left side of the pituitary adenoma and the posterior lobe of normal pituitary. B: Endoscopic view showing the inverted normal pituitary after total removal of the tumor. C: Anatomical scheme of the endoscopic images. D: ICG endoscopic view showing the fluorescent signal from a small part of the normal pituitary gland. DS = diaphragma sellae; $\mathrm{PL}=$ posterior lobe of pituitary. Figure is available in color online only. 

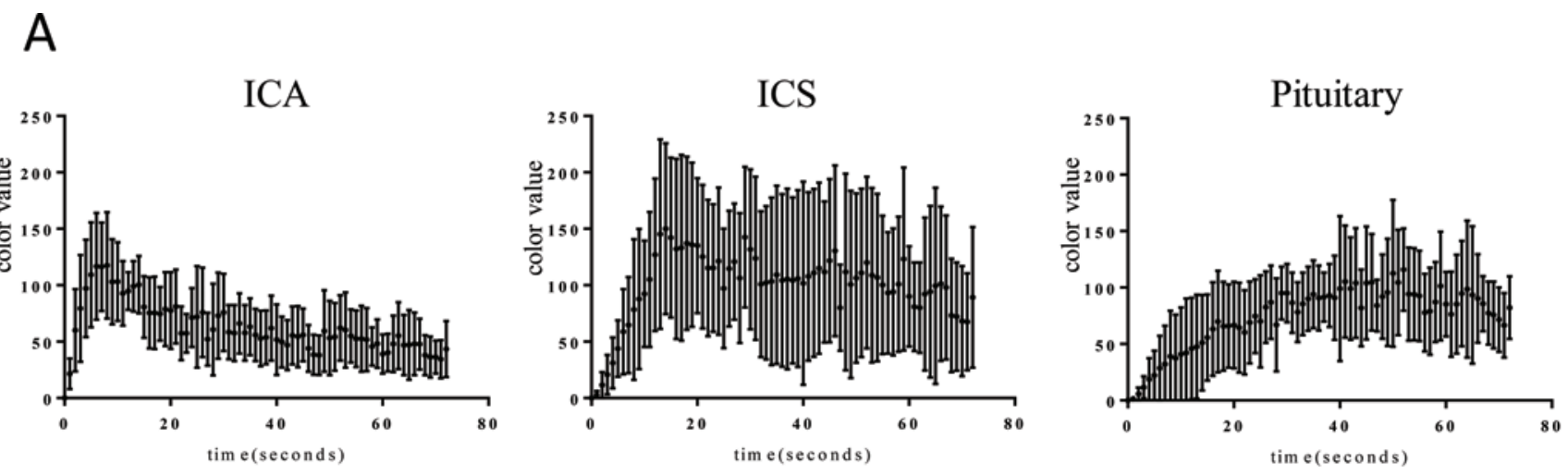

B
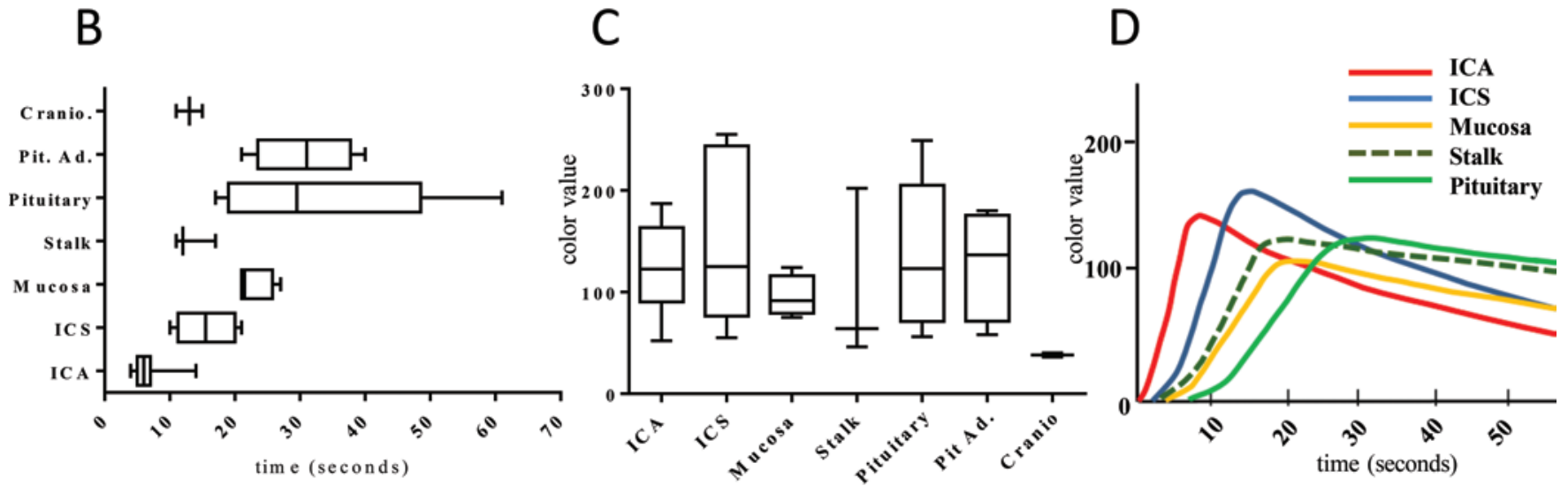

FIG. 6. Graphs showing the relative changes over time in the fluorescence signals. A: Change in the fluorescent intensity of normal structures. The range of the color value from minimum to maximum and the center of each range are shown for the ICA, ICS, and pituitary. B: Graph showing the time at peak color value for each structure (the range from minimum to maximum, the 25th and 75th percentiles, and the median). C: Graph showing the peak color value for each structure (the range from minimum to maximum, the 25th and 75th percentiles, and the median). D: Graph showing the general changes in the color values with the passage of time. Cranio. = craniopharyngioma; Pit Ad. = pituitary adenoma. Figure is available in color online only.

the time at peak color value was 6.0 seconds in the ICA (n $=10), 15.5$ seconds in the ICS $(n=8), 21.5$ seconds in the mucosa $(\mathrm{n}=4), 12.0$ seconds in the stalk $(\mathrm{n}=3), 29.5 \mathrm{sec}-$ onds in the pituitary $(\mathrm{n}=4), 31.0$ seconds in the pituitary adenoma $(\mathrm{n}=4)$, and 13.0 seconds in the craniopharyngioma $(n=2)($ Fig. $6 \mathrm{~B})$. The stalk was visualized before the pituitary. The difference in the time at peak color value of the pituitary and the pituitary adenomas was not statistically significant (Table 1). The median of the peak color value in individual patients was 122.5 for the ICA, 125.0 for the ICS, 91.5 for the mucosa, 64.0 for the stalk, 123.0 for the pituitary, 136.5 for pituitary adenoma, and 38.0 for craniopharyngioma (Fig. 6C). Because our sample size was small, we could not assess the significance of differences in the peak color value, although the color value of the stalk and pituitary tended to be higher than that of the craniopharyngiomas (Table 2). Our results suggest that the ICG endoscope is clinically useful for the differentiation

TABLE 1. The time at peak color value

\begin{tabular}{lccccccccc}
\hline & No. of & \multicolumn{7}{c}{ Time at Peak Color (secs) } \\
\cline { 3 - 10 } Location & Values & Minimum & 25th \%ile & Median & 75th \%ile & Maximum & Mean & SD & SEM \\
\hline ICA & 12 & 4.0 & 5.0 & 6.0 & 7.0 & 14.0 & 6.5 & 2.6 & 0.8 \\
\hline ICS & 8 & 10.0 & 11.3 & 15.5 & 20.0 & 21.0 & 15.6 & 4.6 & 1.6 \\
\hline Mucosa & 4 & 21.0 & 21.0 & 21.5 & 25.8 & 27.0 & 22.8 & 2.9 & 1.4 \\
\hline Stalk & 3 & 11.0 & 11.0 & 12.0 & 17.0 & 17.0 & 13.3 & 3.2 & 1.9 \\
\hline Pituitary & 8 & 17.0 & 19.0 & 29.5 & 48.5 & 61.0 & 33.6 & 16.6 & 5.9 \\
\hline PA & 4 & 21.0 & 23.5 & 31.0 & 37.8 & 40.0 & 30.8 & 7.8 & 3.9 \\
\hline Cranio & 2 & 11.0 & 11.0 & 13.0 & 15.0 & 15.0 & 13.0 & 2.8 & 2.0 \\
\hline
\end{tabular}

Cranio = craniopharyngioma; $\mathrm{PA}=$ pituitary adenoma; $\%$ ile = percentile. 
TABLE 2. Peak color value

\begin{tabular}{lccrrrrrrr}
\hline & No. of & \multicolumn{7}{c}{ Peak Color Value } \\
\cline { 3 - 10 } Location & Values & Minimum & 25th \%ile & Median & 75th \%ile & Maximum & Mean & SD & SEM \\
\hline ICA & 12 & 52.0 & 90.3 & 122.5 & 163.3 & 187.0 & 123.6 & 45.6 & 13.2 \\
\hline ICS & 8 & 55.0 & 76.3 & 125.0 & 243.8 & 255.0 & 147.8 & 82.0 & 29.0 \\
\hline Mucosa & 4 & 75.0 & 79.0 & 91.5 & 116.0 & 124.0 & 95.5 & 20.5 & 10.3 \\
\hline Stalk & 3 & 46.0 & 46.0 & 64.0 & 202.0 & 202.0 & 104.0 & 85.4 & 49.3 \\
\hline Pituitary & 7 & 56.0 & 71.0 & 123.0 & 205.0 & 249.0 & 138.6 & 69.5 & 26.3 \\
\hline PA & 4 & 58.0 & 71.3 & 136.5 & 175.5 & 180.0 & 127.8 & 54.9 & 27.5 \\
\hline Cranio & 2 & 36.0 & 36.0 & 38.0 & 40.0 & 40.0 & 38.0 & 2.8 & 2.0 \\
\hline
\end{tabular}

between the normal pituitary and craniopharyngiomas. Figure 6D shows the general changes in the color values of the different structures with the passage of time.

\section{Discussion}

Endoscopic surgery is one of the minimally invasive treatments for brain tumors. ${ }^{6}$ There are some practical limitations with respect to ETSS. As visualization in this operation is usually $2 \mathrm{D}$ rather than stereoscopic, spatial orientation can be difficult. Surgical instruments interfere with each other in the small operative field, and when angled endoscopes are used, the manipulation of these instruments is particularly challenging because the angle of their insertion and the angle of the operative field are different. Consequently, for the operation to be safe, the surgeon must be highly skilled and the development of new instruments is required.

In vascular surgeries, intraoperative angiography and Doppler ultrasonography are used, ${ }^{1,2}$ and real-time blood flow is confirmed with the aid of microscope-integrated ICG videoangiography. ${ }^{13,15,19,22}$ Endoscope-integrated ICG videoangiography was introduced to assist confirmation of the patency of vessels hidden from microscopic view. $311,12,21$

In patients with brain tumors, the fluorescence signals of 5-aminolevulinic acid (5-ALA) were used to obtain a photodynamic diagnosis. ${ }^{18}$ Tumor resection assisted by 5-ALA fluorescence had a direct effect on the overall survival of patients with primary malignant gliomas..$^{16-18}$ Ritz et al. ${ }^{14}$ and Tamura et al. ${ }^{20}$ resected intraventricular gliomas and deep-seated primary malignant brain tumors under endoscopic observation. Others ${ }^{5,8}$ have used 5-ALA and ICG for the photodynamic diagnosis of patients with pituitary adenomas treated by ETSS, and Litvack et al. ${ }^{9}$ reported that adenomas were less ICG fluorescent than the normal pituitary.

In patients with pituitary adenomas, craniopharyngiomas, and tuberculum sellae meningiomas, we used an ICG endoscope to identify the ICA, perforators, and veins to discriminate between the tumor and the pituitary stalk. The intensity of fluorescent signals from the ICA, ICS, and pituitary changed over time; the ICA and ICS were visualized earlier than the pituitary, and the pituitary stalk was always detected before the pituitary. The sequence of detection was the same but the time of detection appeared to be slightly affected by the injection speed of ICG and the cardiac output of individual patients. In Fig. 6, we schematically demonstrate the approximate changes over time in ICG intensity in the different structures. Clinically the discrimination between the pituitary stalk and craniopharyngioma tends to be difficult. We were able to see the fluorescent signal in the pituitary stalk, but the signal in craniopharyngioma tissues was very weak. Additional studies are needed to determine whether the ICG endoscope contributes to a higher resection rate and the preservation of pituitary function.

Blood flow in the superior hypophyseal arteries and other vessels in the optic nerves and stalk could be observed in real time, and a small part of the residual pituitary gland was recognized after tumor removal. This observation suggests that the blood supply to these important structures may help to predict the preservation of visual and hormonal functions.

We found that because it yields real-time images at high resolution, the ICG endoscope is very useful in patients undergoing ETSS. However, as ICG fluorescent signals persist in solid tissues, background signals might be high. Therefore, it is important to know what structures are to be inspected and how to interpret the findings. The diameter of current ICG endoscopes is larger than that of high-resolution rigid endoscopes (5.8 $\mathrm{mm}$ vs $4.0 \mathrm{~mm}$ ) and neither angled ICG endoscopes nor devices for washing the tip are available. Further improvements in ICG endoscopes and the accumulation of clinical data are needed to evaluate the usefulness of these instruments for ETSS.

\section{Conclusions}

The ICG endoscope was introduced in ETSS to obtain clear information on vessels. The ICA and the patent CS were clearly detected with the ICG endoscope in real time and at high resolution. This instrument may make it possible to detect the attachment of tuberculum sellae meningiomas, to distinguish between the pituitary stalk and craniopharyngiomas, and to evaluate the patency of small arteries such as the superior hypophyseal arteries. Based on the findings reported here, we suggest that the ICG endoscope is very useful for ETSS.

\section{Acknowledgment}

We thank all the members of the Department of Neurosurgery, Kumamoto University Graduate School of Medical Science, who were integral to the medical management of these patients. 


\section{References}

1. Akdemir H, Oktem IS, Tucer B, Menkü A, Başaslan K, Günaldi O: Intraoperative microvascular Doppler sonography in aneurysm surgery. Minim Invasive Neurosurg 49:312-316, 2006

2. Barrow DL, Boyer KL, Joseph GJ: Intraoperative angiography in the management of neurovascular disorders. Neurosurgery 30:153-159, 1992

3. Bruneau M, Appelboom G, Rynkowski M, Van Cutsem N, Mine B, De Witte O: Endoscope-integrated ICG technology: first application during intracranial aneurysm surgery. Neurosurg Rev 36:77-85, 2013

4. Desmettre T, Devoisselle JM, Mordon S: Fluorescence properties and metabolic features of indocyanine green (ICG) as related to angiography. Surv Ophthalmol 45:15-27, 2000

5. Eljamel MS, Leese G, Moseley H: Intraoperative optical identification of pituitary adenomas. J Neurooncol 92:417421, 2009

6. Kassam AB, Prevedello DM, Carrau RL, Snyderman CH, Thomas A, Gardner P, et al: Endoscopic endonasal skull base surgery: analysis of complications in the authors' initial 800 patients. J Neurosurg 114:1544-1568, 2011

7. Komotar RJ, Starke RM, Raper DM, Anand VK, Schwartz $\mathrm{TH}$ : Endoscopic endonasal compared with microscopic transsphenoidal and open transcranial resection of craniopharyngiomas. World Neurosurg 77:329-341, 2012

8. Koutourousiou M, Gardner PA, Fernandez-Miranda JC, Paluzzi A, Wang EW, Snyderman CH: Endoscopic endonasal surgery for giant pituitary adenomas: advantages and limitations. J Neurosurg 118:621-631, 2013

9. Litvack ZN, Zada G, Laws ER Jr: Indocyanine green fluorescence endoscopy for visual differentiation of pituitary tumor from surrounding structures. J Neurosurg 116:935-941, 2012

10. McLaughlin N, Eisenberg AA, Cohan P, Chaloner CB, Kelly DF: Value of endoscopy for maximizing tumor removal in endonasal transsphenoidal pituitary adenoma surgery. J Neurosurg 118:613-620, 2013

11. Mielke D, Malinova V, Rohde V: Comparison of intraoperative microscopic and endoscopic ICG angiography in aneurysm surgery. Neurosurgery 10 (Suppl 3):418-425, 2014

12. Nishiyama Y, Kinouchi H, Senbokuya N, Kato T, Kanemaru $\mathrm{K}$, Yoshioka $\mathrm{H}$, et al: Endoscopic indocyanine green video angiography in aneurysm surgery: an innovative method for intraoperative assessment of blood flow in vasculature hidden from microscopic view. J Neurosurg 117:302-308, 2012

13. Raabe A, Nakaji P, Beck J, Kim LJ, Hsu FP, Kamerman JD, et al: Prospective evaluation of surgical microscopeintegrated intraoperative near-infrared indocyanine green videoangiography during aneurysm surgery. J Neurosurg 103:982-989, 2005

14. Ritz R, Feigl GC, Schuhmann MU, Ehrhardt A, Danz S,
Noell S, et al: Use of 5-ALA fluorescence guided endoscopic biopsy of a deep-seated primary malignant brain tumor. J Neurosurg 114:1410-1413, 2011

15. Schuette AJ, Cawley CM, Barrow DL: Indocyanine green videoangiography in the management of dural arteriovenous fistulae. Neurosurgery 67:658-662, 2010

16. Stummer W, Pichlmeier U, Meinel T, Wiestler OD, Zanella F, Reulen HJ: Fluorescence-guided surgery with 5-aminolevulinic acid for resection of malignant glioma: a randomised controlled multicentre phase III trial. Lancet Oncol 7:392401, 2006

17. Stummer W, Reulen HJ, Meinel T, Pichlmeier U, Schumacher W, Tonn JC, et al: Extent of resection and survival in glioblastoma multiforme: identification of and adjustment for bias. Neurosurgery 62:564-576, 2008

18. Stummer W, Stocker S, Wagner S, Stepp H, Fritsch C, Goetz $\mathrm{C}$, et al: Intraoperative detection of malignant gliomas by 5 -aminolevulinic acid-induced porphyrin fluorescence. Neurosurgery 42:518-526, 1998

19. Suzuki K, Kodama N, Sasaki T, Matsumoto M, Ichikawa T, Munakata R, et al: Confirmation of blood flow in perforating arteries using fluorescein cerebral angiography during aneurysm surgery. J Neurosurg 107:68-73, 2007

20. Tamura Y, Kuroiwa T, Kajimoto Y, Miki Y, Miyatake S, Tsuji M: Endoscopic identification and biopsy sampling of an intraventricular malignant glioma using a 5-aminolevulinic acid-induced protoporphyrin IX fluorescence imaging system. Technical note. J Neurosurg 106:507-510, 2007

21. Washington CW, Zipfel GJ, Chicoine MR, Derdeyn CP, Rich $\mathrm{KM}$, Moran CJ, et al: Comparing indocyanine green videoangiography to the gold standard of intraoperative digital subtraction angiography used in aneurysm surgery. J Neurosurg 118:420-427, 2013

22. Wrobel CJ, Meltzer H, Lamond R, Alksne JF: Intraoperative assessment of aneurysm clip placement by intravenous fluorescein angiography. Neurosurgery 35:970-973, 1994

\section{Author Contributions}

Conception and design: Hide, Yano. Acquisition of data: Hide, Yano, Shinojima. Analysis and interpretation of data: Hide, Yano, Shinojima. Critically revising the article: Yano, Kuratsu. Reviewed submitted version of manuscript: Hide, Yano, Kuratsu. Study supervision: Hide, Kuratsu.

\section{Correspondence}

Takuichiro Hide, Department of Neurosurgery, Kumamoto University Graduate School of Medical Science, 1-1-1 Honjo, Chuo-ku, Kumamoto 860-8556, Japan.email: thide@fc.kuh. kumamoto-u.ac.jp. 